\title{
Representation of basal melting at the grounding line in ice flow models
}

\author{
Hélène Seroussi $^{1}$ and Mathieu Morlighem ${ }^{2}$ \\ ${ }^{1}$ Jet Propulsion Laboratory - California Institute of Technology, Pasadena, CA 91109, USA \\ ${ }^{2}$ Department of Earth System Science, University of California Irvine, Irvine, CA 92697, USA
}

Correspondence: Hélène Seroussi (helene.seroussi@jpl.nasa.gov)

Received: 4 June 2018 - Discussion started: 13 June 2018

Revised: 4 September 2018 - Accepted: 7 September 2018 - Published: 1 October 2018

\begin{abstract}
While a lot of attention has been given to the numerical implementation of grounding lines and basal friction in the grounding zone, little has been done about the impact of the numerical treatment of ocean-induced basal melting in this region. Several strategies are currently being employed in the ice sheet modeling community, and the resulting grounding line dynamics may differ strongly, which ultimately adds significant uncertainty to the projected contribution of marine ice sheets to sea level rise. We investigate here several implementations of basal melt parameterization on partially floating elements in a finite-element framework, based on the Marine Ice Sheet-Ocean Model Intercomparison Project (MISOMIP) setup: (1) melt applied only to entirely floating elements, (2) melt applied over all elements that are crossed by the grounding line, and (3) melt integrated partially over the floating portion of a finite element using two different sub-element integration methods. All methods converge towards the same state when the mesh resolution is fine enough. However, (2) and (3) will systematically overestimate the rate of grounding line retreat in coarser resolutions, while (1) converges faster to the solution in most cases. The differences between sub-element parameterizations are exacerbated for experiments with high melting rates in the vicinity of the grounding line and for a Weertman sliding law. As most real-world simulations use horizontal mesh resolutions of several hundreds of meters at best, and high melt rates are generally present close to the grounding lines, we recommend not using (3) to avoid overestimating the rate of grounding line retreat and to carefully assess the impact of mesh resolution and sub-element melt parameterizations on all simulation results.
\end{abstract}

\section{Introduction}

Basal melt under floating ice tongues is important as it is one of the main factors driving the current increase in ice discharge in West Antarctica (e.g., Pritchard et al., 2012). Changes in basal melt impact ice shelf thickness, and thinning leads to a reduction of ice shelf buttressing, thereby leading to an acceleration of the ice streams feeding it. This acceleration is responsible for the dynamic thinning of the ice upstream of the grounding line, eventually leading to grounding line retreat, which causes a further increase in ice speed and therefore ice discharge. Accurate representation of ocean-induced ice shelf basal melt in ice flow models is therefore critical. This remains an active field of research as observations of basal melt remain scarce and new parameterizations are starting to emerge (Lazeroms et al., 2018; Reese et al., 2017).

Over the past decade, the ice sheet modeling community has made tremendous progress in terms of representation of grounding line dynamics in ice sheet models. Model intercomparisons have shown that lateral stress and high mesh resolution (below $2 \mathrm{~km}$ ) in the grounding zone are required to accurately capture the behavior of the grounding line (Pattyn et al., 2012, 2013). New sub-element parameterizations of grounding line position and the representation of basal friction in partially floating elements have shown promising results for both flow band and plan view models (Pattyn et al., 2006; Gladstone et al., 2010; Leguy et al., 2014; Seroussi et al., 2014a; Feldmann et al., 2014), as they relaxed the mesh resolution requirements in this region. These studies, however, are all based on ideal geometries and completely ignore basal melt under floating ice (i.e., no melt is applied under floating ice). In reality, melt can be strong, es- 


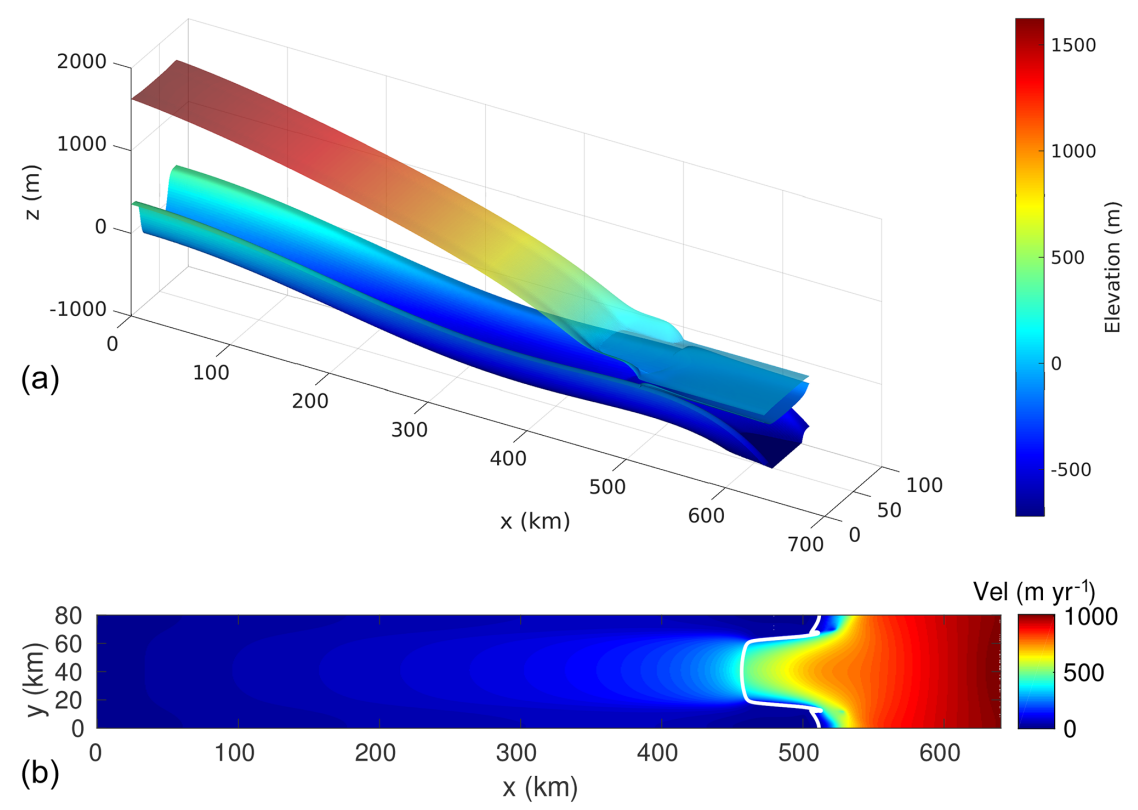

Figure 1. Model domain and initial steady-state geometry for the $125 \mathrm{~m}$ resolution mesh with a Weertman sliding law. (a) Bedrock elevation and initial steady-state ice surface and basal elevation (Note the vertical exaggeration). (b) Initial steady-state velocity (in $\mathrm{m} \mathrm{yr}^{-1}$ ). The white line shows the initial grounding line position.

pecially in the vicinity of the grounding line, where it can reach $\sim 100 \mathrm{~m} \mathrm{yr}^{-1}$ (Dutrieux et al., 2013; Rignot et al., 2013; Berger et al., 2017). Several studies have shown that, for the same melt parameterization, the choice of numerical implementation of melt has a strong impact on model results for both projections of the West Antarctic Ice Sheet (Cornford et al., 2016; Arthern and Williams, 2017) and idealized glaciers (Gladstone et al., 2017). This problem has, however, not been fully investigated or quantified yet, and it remains unclear what parameterizations should be employed in partially floating elements.

We investigate these questions here by using different numerical implementations of basal melting in partially floating elements and two friction laws on a setup similar to the Marine Ice Sheet-Ocean Model Intercomparison Project (MISOMIP; Asay-Davis et al., 2016). We first summarize the model setup and detail the four different parameterizations of basal melt in elements partially floating and partially grounded. We then describe the experiments used to test these parameterizations. We present the results, discuss their impact on the modeling of grounding line evolution, and conclude on the relevance of using sub-element parameterizations of ocean-induced melt under ice shelves.

\section{Model}

We use the Ice Sheet System Model (ISSM; Larour et al., 2012) to simulate the ice flow of an idealized case representative of outlet glaciers in West Antarctica (Asay-Davis et al.,
2016). The model setup is identical to the one described in Asay-Davis et al. (2016) that we briefly summarize here. All the parameters are similar to their description, except where specified otherwise.

The experiments simulate a glacier in a marineterminating confined valley, with a bedrock lying between -720 and $350 \mathrm{~m}$ as shown in Fig. 1a. The accumulation is uniform over the domain and set to $0.3 \mathrm{~m} \mathrm{yr}^{-1}$. Basal melting is applied under floating ice, with a different magnitude depending on the experiments. The model domain extends between 0 and $640 \mathrm{~km}$ and between 0 and $80 \mathrm{~km}$ in the $x$ and $y$ direction, respectively. This domain is discretized using a triangular mesh with resolutions of $2 \mathrm{~km}, 1 \mathrm{~km}, 500 \mathrm{~m}$, $250 \mathrm{~m}$, and $125 \mathrm{~m}$, resulting in meshes with a number of elements varying from 28000 to 1745000 . All mesh resolutions are spatially uniform except in the case of the $125 \mathrm{~m}$ resolution mesh, for which the model resolution is $125 \mathrm{~m}$ only in the portion of the domain located between $x=300 \mathrm{~km}$ and $x=600 \mathrm{~km}$ (i.e., where we expect to see the grounding line); the resolution is otherwise $1 \mathrm{~km}$ for $x<200 \mathrm{~km}$ and $500 \mathrm{~m}$ for the rest of the domain.

The two-dimensional shelfy-stream approximation (SSA; MacAyeal, 1989) is used as an approximation of the fullStokes equations to solve the stress balance equations, and the grounding line position is determined assuming hydrostatic equilibrium. The ice rheology is spatially uniform in the domain and follows Glen's flow law with a rate factor, $A$, equal to $2.0 \times 10^{-17} \mathrm{~Pa}^{-3} \mathrm{yr}^{-1}$, equivalent to an ice temperature of about $-9^{\circ} \mathrm{C}$. Boundary conditions are a no- 


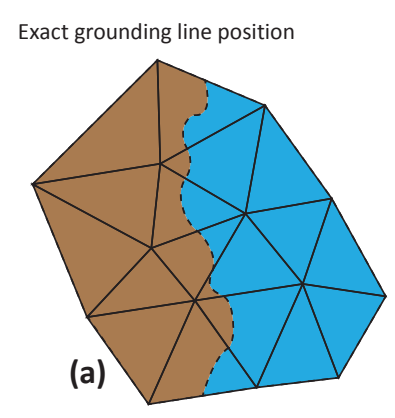

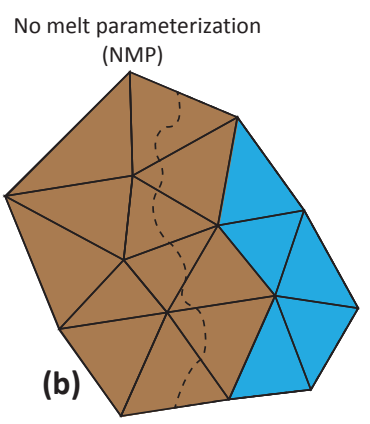

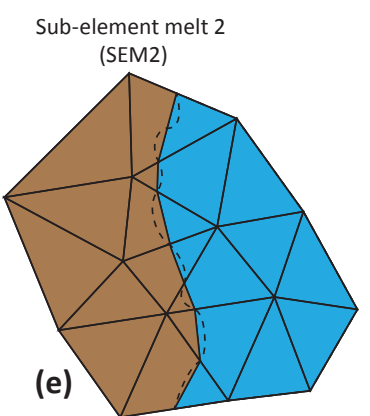

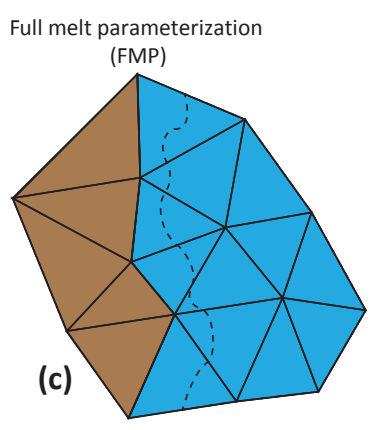

..... Exact grounding line

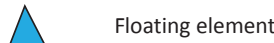

Grounded element

Floating element with

reduced melting

Figure 2. Grounding line discretization. Grounding line's exact location (a), no-melt parameterization (NMP, b), full-melt parameterization (FMP, c), sub-element melt 1 (SEM1, d), and sub-element melt 2 (SEM2, e).

slip condition at $x=0 \mathrm{~km}$, a free-slip condition at $y=0$ and $y=80 \mathrm{~km}$, and a fixed ice front at $x=640 \mathrm{~km}$. We test here two different friction laws. The first one is a power sliding law, following Weertman (1957):

$\boldsymbol{\tau}_{\mathrm{b}}=-\beta^{2}\left\|\boldsymbol{u}_{\mathrm{b}}\right\|^{1 / m-1} \boldsymbol{u}_{\mathrm{b}}$

with $\boldsymbol{\tau}_{\mathrm{b}}$ the basal stress, $\boldsymbol{u}_{\mathrm{b}}$ the basal velocity vector, $m=3$, and $\beta^{2}$ the friction coefficient uniform in space and equal to $1.0 \times 10^{4} \mathrm{~Pa} \mathrm{~m}^{-1 / 3} \mathrm{yr}^{1 / 3}$. This friction law induces a sharp discontinuity in basal friction at the grounding line that is not realistic and not appropriate for problems investigating grounding line evolution but remains nevertheless widely used in the community (Brondex et al., 2017).

The second sliding law is a modified power law designed to prevent the basal traction exceeding a fraction of the effective pressure, proposed by Tsai et al. (2015):

$\boldsymbol{\tau}_{\mathrm{b}}=-\min \left(\alpha^{2} N, \beta^{2}\left\|\boldsymbol{u}_{\mathrm{b}}\right\|^{1 / m}\right)\left\|\boldsymbol{u}_{\mathrm{b}}\right\|^{-1} \boldsymbol{u}_{\mathrm{b}}$,

with $\alpha^{2}=0.5$ and $N$ the effective pressure at the ice base, assuming a perfect connectivity of the subglacial hydrologic system with the ocean.

The representation of basal friction at the grounding line is the same in all experiments and follows the SEP2 parameterization of Seroussi et al. (2014a). It has been shown that this parameterization is satisfactory for capturing grounding line dynamics, as it converges faster to the solution as the mesh resolution increases compared to other methods.

In this study, we use the same methodology as Seroussi et al. (2014a) but apply it to sub-element melting parameteri- zations in elements partially floating and partially grounded. Figure 2 shows the four different parameterizations adopted in this study. In the case of the "full-melt parameterization" (FMP), melt is applied everywhere over all partially floating elements, regardless of the exact position of the grounded line, while in the "no-melt parameterization" (NMP) there is no melt applied to any area of the partially floating elements. The last two cases use a sub-element parameterization. In the "sub-element melt 1" (SEM1), melt is applied to the entire area of partially floating elements, but the magnitude of the melt is reduced by the fraction area of the floating ice in the element, so that the total melt applied is proportional to the floating ice area. In the "sub-element melt 2" (SEM2) parameterization, the ocean-induced melt rate is integrated exactly over the floating part of the element in the mass transport equation, so that melt rate is only applied to the floating part of the element.

Testing two sliding laws, four melt parameterizations, and five mesh resolutions results in a total of 40 different configurations. The same experiments are performed on each of these configurations.

\section{Experiments}

We first run every configuration to a steady-state ice stream without any melt. The initial ice thickness is equal to $1 \mathrm{~m}$ and the ice stream grows over several tens of thousands of years (at least 50000 years) in response to surface mass balance accumulation, while no basal melting is applied under float- 
ing ice. This steady state is therefore independent of the subelement basal melt parameterization applied. Convergence of the solution to the steady state is discussed in the analysis of experiment 0 in Sect. 4.

Starting from this steady state, three transient experiments with varying ice shelf basal melting conditions are performed for a period of 100 years. In experiment 0 , no basal melting is applied under floating ice, similar to the steady-state initialization of the model. Experiment 0 is therefore mainly designed to check the initial steady state. Basal melting is applied under floating ice in experiment 1 and experiment 2 , and we assess the impact of the melt parameterization, model resolution, and sliding laws on the glacier evolution. Experiment 1 is similar to the MISMIP+ Ice 1r experiment in AsayDavis et al. (2016): basal melting varies spatially and represents a balance between the latent heat of melting and a parameterized ocean turbulent heat flux:

$m_{i}=\Omega \tanh \left(\frac{H_{\mathrm{c}}}{H_{\mathrm{c} 0}}\right) \max \left(z_{0}-z_{d}, 0\right)$,

with $\Omega$ a coefficient equal to $0.2 \mathrm{yr}^{-1}, H_{\mathrm{c}}$ the water column thickness, $z_{d}$ the ice shelf basal elevation, $z_{0}$ the depth above which the melt rate is equal to zero $(100 \mathrm{~m})$, and $H_{\mathrm{c} 0}$ a constant equal to $75 \mathrm{~m}$ (see also Eqs. 12-17 in Asay-Davis et al., 2016, for the derivation of this parameterization).

Experiment 2 is based on a basal melt under floating ice that varies linearly with depth, with a maximum melt magnitude of $30 \mathrm{~m} \mathrm{yr}^{-1}$ in the deepest part, where the ice base is at or below $500 \mathrm{~m}$ below sea level and linearly decreases to $0 \mathrm{~m} \mathrm{yr}^{-1}$ melt for ice base equal to $50 \mathrm{~m}$ below sea level. There is therefore no melt when the ice base is above $50 \mathrm{~m}$ below sea level:

$m_{i}= \begin{cases}0 \mathrm{~m} \mathrm{yr}^{-1}, & \text { if } z_{d}>-50 \mathrm{~m} \\ -1 / 15\left(z_{d}+50\right) \mathrm{myr}^{-1}, & \text { if }-500<z_{d}<-50 \mathrm{~m}, \\ 30 \mathrm{myr}^{-1}, & \text { if } z_{d}<-500 \mathrm{~m}\end{cases}$

with $z_{d}$ the ice shelf basal elevation. This experiment simulates ice shelves resting in warm waters, similarly to what has been observed in the Amundsen or Bellingshausen Sea areas (e.g., Dutrieux et al., 2013; Rignot et al., 2013) and used in previous modeling experiments (e.g., Favier et al., 2014; Joughin et al., 2014; Seroussi et al., 2014b, 2017).

Experiments 0,1 , and 2 are all run for 100 years. We use the following convention to refer to the different experiments. For the steady state (SS) and experiment 0, names are as follows: EXP_sliding_resolution, where EXP is the number of the experiment (SS or EXP0), the sliding refers to the sliding law (Weertman or Tsai), and "resolution" is the mesh resolution $(2 \mathrm{~km}, 1 \mathrm{~km}, 500 \mathrm{~m}, 250 \mathrm{~m}$, or $125 \mathrm{~m})$, e.g., EXP0_Weertman_250m. For experiment 1 and experiment 2, the names are similar - EXP_sliding_resolution_SEM - except that we add SEM, the sub-element melt parameterization at the grounding line (NMP, FMP, SEM1 or SEM2), e.g., EXP1_Weertman_250m_SEM1, as the results of these sim-
Table 1. Steady-state grounding line position in the glacier centerline and volume above floatation (VAF).

\begin{tabular}{lllr}
\hline Friction law & Resolution & GL $(y=40 \mathrm{~km})$ & VAF $(\mathrm{Gt})$ \\
\hline Weertman & $2 \mathrm{~km}$ & $448.0 \mathrm{~km}$ & 46327 \\
Weertman & $1 \mathrm{~km}$ & $452.8 \mathrm{~km}$ & 47044 \\
Weertman & $500 \mathrm{~m}$ & $456.3 \mathrm{~km}$ & 47540 \\
Weertman & $250 \mathrm{~m}$ & $456.6 \mathrm{~km}$ & 47674 \\
Weertman & $125 \mathrm{~m}$ & $456.7 \mathrm{~km}$ & 47737 \\
\hline Tsai & $2 \mathrm{~km}$ & $437.9 \mathrm{~km}$ & 44996 \\
Tsai & $1 \mathrm{~km}$ & $440.0 \mathrm{~km}$ & 45238 \\
Tsai & $500 \mathrm{~m}$ & $442.9 \mathrm{~km}$ & 45700 \\
Tsai & $250 \mathrm{~m}$ & $444.1 \mathrm{~km}$ & 45899 \\
Tsai & $125 \mathrm{~m}$ & $444.1 \mathrm{~km}$ & 45889 \\
\hline
\end{tabular}

ulations now depend on the sub-element melt parameterization adopted.

\section{Results}

Figure 1 shows the initial steady-state configuration for SS_Weertman_125m. Its geometry is shown in Fig. 1a, and the velocity and grounding line are shown in Fig. 1b. The grounding line position varies between $458 \mathrm{~km}$ in the centerline of the glacier and $528 \mathrm{~km}$ on its sides; the ice velocity is maximum at the ice front, reaching $1012 \mathrm{~m} \mathrm{yr}^{-1}$. This configuration is comparable to previous results based on the same geometry (Gudmundsson et al., 2012; Gudmundsson, 2013; Asay-Davis et al., 2016). The mesh resolution and the type of basal sliding law both impact the grounding line position as shown in Fig. 3. The grounding line position on the glacier centerline varies between $438 \mathrm{~km}$ for SS_Tsai_2km and $458 \mathrm{~km}$ for SS_Weertman_125m, with a larger spread between the different resolutions for the Tsai friction law $(9.6 \mathrm{~km})$ than for the Weertman friction law $(6.2 \mathrm{~km})$ (Fig. 3 and Table 1).

Experiment 0 is mostly designed to ensure that the model has reached a steady state, as no melt is applied, similar to the initial steady state. The ice mass above floatation (Fig. 4a) remains constant over the 100-year simulation for the 10 configurations, while the grounded ice area (Fig. 4b) experiences small oscillations, especially for the Weertman sliding law. Such oscillations, which average to zero change in the grounded area over time, have been noted by Asay-Davis et al. (2016) and are orders of magnitude smaller than the changes simulated in experiment 1 and experiment 2. Figure 4 confirms that sub-kilometer resolution is needed to accurately capture the grounding line positions, similarly to what has been suggested by previous studies (e.g., Vieli and Payne, 2005; Gladstone et al., 2010; Pattyn et al., 2012, 2013; Feldmann et al., 2014; Seroussi et al., 2014a). The difference in modeled volume (see Table 1) between the $1 \mathrm{~km}$ and $500 \mathrm{~m}$ models is $1.02 \%$ and $1.05 \%$, and the difference in 

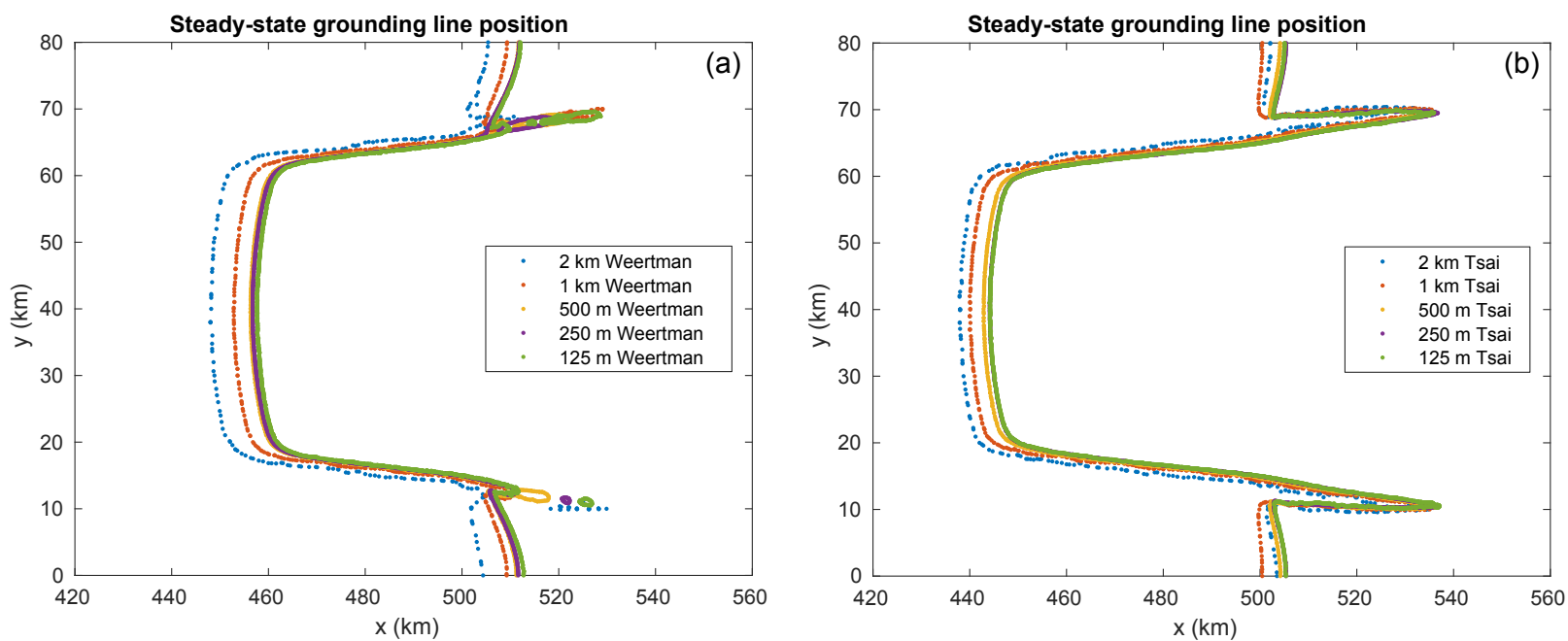

Figure 3. Steady-state grounding line positions for the Weertman (a) and Tsai (b) friction law for the $2 \mathrm{~km}$ (blue), $1 \mathrm{~km}$ (red), $500 \mathrm{~m}$ (yellow), $250 \mathrm{~m}$ (purple), and $125 \mathrm{~m}$ (green) mesh resolutions. Note that the Tsai friction grounding lines for the 250 and $125 \mathrm{~m}$ resolution meshes are superimposed.

grounded area is $0.61 \%$ and $0.62 \%$, respectively, for the Weertman and Tsai friction laws. Differences between models at 500, 250, and $125 \mathrm{~m}$ resolution are all well below $1 \%$ (the curves for SS_Tsai_125m and SS_Tsai_250m are superimposed in Fig. 4). By comparison, the difference in volume above floatation and grounded area between the two friction laws at $125 \mathrm{~m}$ resolution is respectively $3.9 \%$ and $1.6 \%$.

Experiment 1 simulates the evolution of the glacier when ocean-induced melt is applied under floating ice. The equation that governs the melt rate in this experiment provides limited melt close to the grounding line, as the water column thickness becomes smaller (see Eq. 3). Figure 5 shows the evolution of the ice volume above floatation for this experiment for the different sub-element melt parameterizations, the different mesh resolutions, and the two friction laws. The volume above floatation lost (see also Table 2) varies between 4140 and $6690 \mathrm{Gt}$ for the EXP1_Weertman_2km_NMP and EXP1_Tsai_2km_FMP scenarios, respectively. Experiments performed with the Tsai friction law show a larger mass loss (between 5480 and $6690 \mathrm{Gt}$ over the 100 -year period) than the ones performed with a Weertman friction law (between 4140 and $5410 \mathrm{Gt}$ ). The impact of the sub-element melt parameterization adopted, however, is more pronounced in the case of Weertman sliding law. The Tsai sliding law shows similar results for all sub-element parameterizations if the mesh resolution is $1 \mathrm{~km}$ and under, suggesting that any sub-element melt parameterization can be adopted in this case. Results performed at $2 \mathrm{~km}$ resolution all overestimate the mass loss, except when the NMP is adopted, in which case they underestimate the mass loss. If the Weertman sliding law is applied, the results are strongly dependent on both the sub- element parameterization and the mesh resolution. SEM1, SEM2, and FMP behave very similarly, with mass loss being reduced as the resolution increases (from $\sim 5400 \mathrm{Gt}$ at $2 \mathrm{~km}$ resolution to $\sim 4150 \mathrm{Gt}$ at $250 \mathrm{~m}$ resolution). The difference between the runs becomes smaller as the mesh resolution increases, but the results are within $5 \%$ of the results obtained with a resolution of $125 \mathrm{~m}$ only for resolutions below $500 \mathrm{~m}$. The NMP presents a completely different behavior, with results almost identical for all mesh resolutions for the Weertman sliding law (less than $150 \mathrm{Gt}$ variation after 100 years). The runs relying on NMP underestimate the mass change for the Tsai friction law, with $650 \mathrm{Gt}$ less mass loss for the EXP1_Tsai_2km_NMP compared to EXP1_Tsai_1km_NMP. During the experiment, the grounding line retreat in the centerline of the glacier varies between 40 and $55 \mathrm{~km}$ depending on the mesh resolution and the melt parameterization for the Weertman sliding law, and between 55 and $70 \mathrm{~km}$ for the Tsai sliding law, with larger retreats for the FMP, SMP1, and SMP2 at coarse resolution and smaller retreats for FMP, SMP1, and SMP2 at fine resolution and NMP.

In experiment 2, a high ice shelf melt rate of up to $30 \mathrm{~m} \mathrm{yr}^{-1}$ is applied under the ice shelf, including close to the grounding line. Figure 6 and Table 3 show the results of this experiment for the different sub-element parameterizations, the different mesh resolutions, and the two sliding laws. The overall mass loss is similar to experiment 1 and varies between 4110 and $7590 \mathrm{Gt}$ for EXP1_Weertman_250m_NMP and EXP1_Tsai_2km_FMP scenarios, respectively, with a larger ice loss for the Tsai friction law overall. The impact of mesh resolution and sub-element parameterization is more pronounced than in 

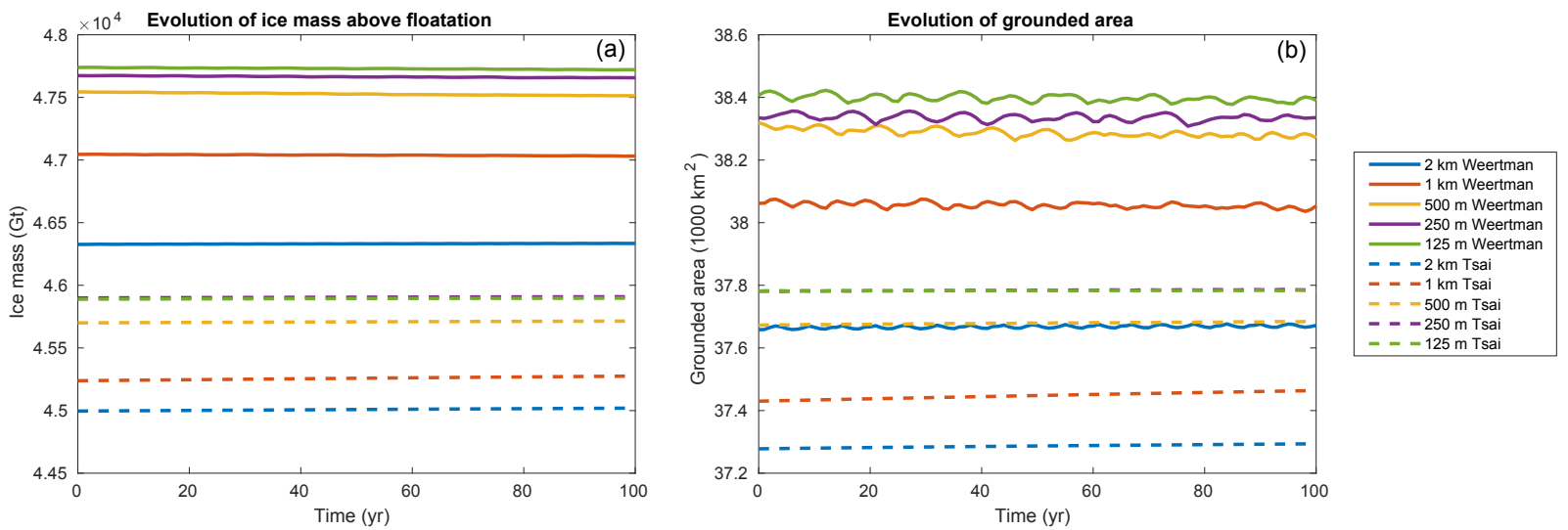

Figure 4. Evolution of ice volume above floatation (a) and grounded area (b) for experiment 0 (steady-state case with no melt applied). Solid and dashed lines represent simulations with Weertman and Tsai friction, respectively, for resolutions of $2 \mathrm{~km}$ (blue), $1 \mathrm{~km}$ (red), $500 \mathrm{~m}$ (yellow), $250 \mathrm{~m}$ (purple), and $125 \mathrm{~m}$ (green). Results for 250 and $125 \mathrm{~m}$ resolutions are superimposed for the Tsai friction.
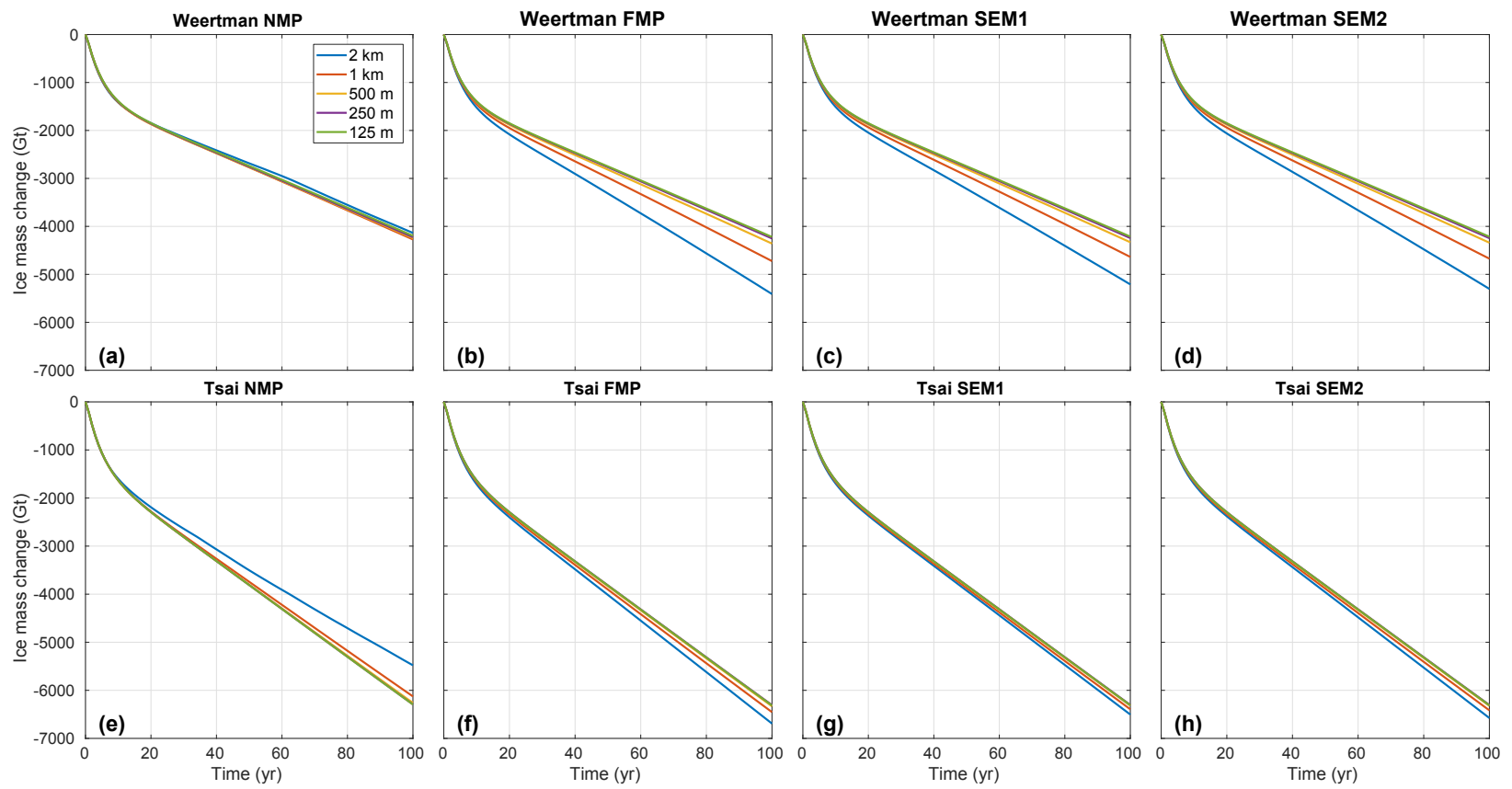

Figure 5. Evolution of ice volume above floatation in experiment 1 for the NMP (a, e), FMP (b, f), SEM1 (c, g), and SEM2 (d, h) for the Weertman (a-d) and Tsai (f-h) friction laws. Each plot represents the evolution for the five mesh resolutions: $2 \mathrm{~km}$ (blue), $1 \mathrm{~km}$ (red), $500 \mathrm{~m}$ (yellow), $250 \mathrm{~m}$ (purple), and $125 \mathrm{~m}$ (green).

experiment 1 . At $2 \mathrm{~km}$ resolution, the difference in mass loss varies by $45 \%$ and $42 \%$ between NMP and FMP for the Weertman and Tsai sliding laws, respectively. This spread is reduced as the mesh resolution increases, but a $125 \mathrm{~m}$ resolution is not sufficient to have similar results for NMP and FMP (14\% and $9 \%$ difference between NMP and FMP at $125 \mathrm{~m}$ resolution for the Weertman and Tsai friction laws, respectively), suggesting that not all parameterizations have fully converged despite the level of mesh resolution. The SEM1 and SEM2 results are intermediate between FMP and NMP and behave similarly in all cases. Figure 6 also shows that NMP is by far the least sensitive to mesh resolution for the Weertman sliding law, with, e.g., a mass change of only $20 \mathrm{Gt}$ between EXP2_Weertman_2km_NMP and EXP2_Weertman_125m_NMP, whereas the difference reaches $1216 \mathrm{Gt}$ between EXP2_Weertman_2km_SEM1 and EXP2_Weertman_125m_SEM1, and $1790 \mathrm{Gt}$ between EXP2_Weertman_2km_FMP and EXP2_Weertman_125m_FMP. Results performed with the two sub-element melt parameterizations show a reduced dependence on mesh resolution. This improvement is not sufficient, however, to have accurate results with 

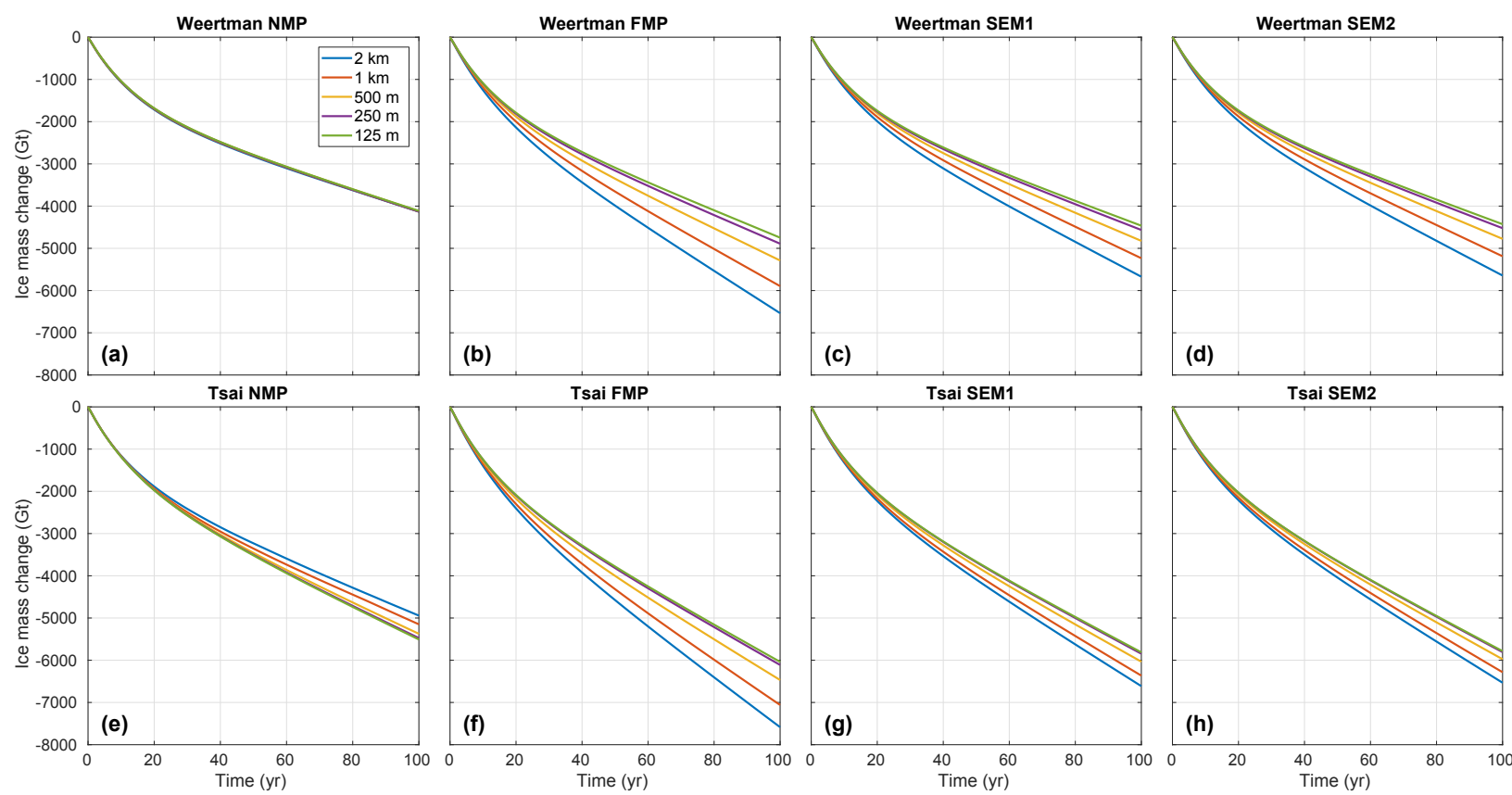

Figure 6. Evolution of ice volume above floatation in experiment 2 for the NMP (a, e), FMP (b, f), SEM1 (c, g), and SEM2 (d, h) for the Weertman (a-d) and Tsai (f-h) friction laws. Each plot represents the evolution for the five mesh resolutions: $2 \mathrm{~km}(\mathrm{blue}), 1 \mathrm{~km}(\mathrm{red}), 500 \mathrm{~m}$ (yellow), $250 \mathrm{~m}$ (purple), and $125 \mathrm{~m}$ (green).

Table 2. Change in volume above floatation ( $\triangle \mathrm{VAF}$ in $\mathrm{Gt})$ in experiment 1 for the Weertman (a) and Tsai (b) friction laws.

\begin{tabular}{lrrrr}
\hline \multirow{2}{*}{ a) } & \multicolumn{3}{c}{ Melt parameterization (Weertman) } \\
\cline { 2 - 5 } Resolution & NMP & FMP & SEM1 & SEM2 \\
\hline $2 \mathrm{~km}$ & -4137 & -5411 & -5210 & -5304 \\
$1 \mathrm{~km}$ & -4272 & -4724 & -4637 & -4673 \\
$500 \mathrm{~m}$ & -4246 & -4359 & -4331 & -4340 \\
$250 \mathrm{~m}$ & -4225 & -4252 & -4244 & -4246 \\
$125 \mathrm{~m}$ & -4196 & -4221 & -4213 & -4215
\end{tabular}

\begin{tabular}{lcrrr}
\hline \multirow{2}{*}{ Resolution } & \multicolumn{4}{c}{ Melt parameterization (Tsai) } \\
\cline { 2 - 5 } & NMP & FMP & SEM1 & SEM2 \\
\hline $2 \mathrm{~km}$ & -5480 & -6692 & -6504 & -6576 \\
$1 \mathrm{~km}$ & -6127 & -6454 & -6394 & -6417 \\
$500 \mathrm{~m}$ & -6261 & -6333 & -6318 & -6324 \\
$250 \mathrm{~m}$ & -6293 & -6315 & -6304 & -6305 \\
$125 \mathrm{~m}$ & -6294 & -6307 & -6309 & -6311 \\
\hline
\end{tabular}

relatively coarse mesh resolutions. The impact of mesh resolution and sub-element melt parameterization is more pronounced with the Weertman than the Tsai sliding friction law. Similarly to what was observed for experiment 1 , experiments performed with the Tsai friction law show less sensitivity to sub-element parameterization and mesh resolution than the Weertman friction law, except for NMP simulations, which experience a mass loss reduced by
Table 3. Change in volume above floatation $(\Delta \mathrm{VAF}$ in $\mathrm{Gt})$ in experiment 2 for the Weertman (a) and Tsai (b) friction laws.

\begin{tabular}{lcccc}
\hline \multirow{2}{*}{ (a) } & \multicolumn{4}{c}{ Melt parameterization (Weertman) } \\
\cline { 2 - 5 } & NMP & FMP & SEM1 & SEM2 \\
\hline $2 \mathrm{~km}$ & -4132 & -6536 & -5672 & -5644 \\
$1 \mathrm{~km}$ & -4130 & -5895 & -5235 & -5188 \\
$500 \mathrm{~m}$ & -4120 & -5289 & -4824 & -4775 \\
$250 \mathrm{~m}$ & -4130 & -4890 & -4565 & -4523 \\
$125 \mathrm{~m}$ & -4115 & -4748 & -4464 & -4428 \\
\hline (b) & \multicolumn{2}{c}{ Melt } & parameterization (Tsai) \\
\cline { 2 - 5 } Resolution & NMP & FMP & SEM1 & SEM2 \\
\hline $2 \mathrm{~km}$ & -4943 & -7585 & -6614 & -6533 \\
$1 \mathrm{~km}$ & -5150 & -7060 & -6365 & -6284 \\
$500 \mathrm{~m}$ & -5374 & -6469 & -6034 & -5976 \\
$250 \mathrm{~m}$ & -5474 & -6112 & -5846 & -5808 \\
$125 \mathrm{~m}$ & -5510 & -6038 & -5812 & -5783 \\
\hline
\end{tabular}

$570 \mathrm{Gt}$ over 100 years for the EXP2_Tsai_2km_NMP compared to the EXP2_Tsai_125m_NMP. The reduction in ice loss after 100 years between EXP2_Tsai_2km_FMP and EXP2_Tsai_125m_FMP and between EXP2_Tsai_2km_SEM1 and EXP2_Tsai_125m_SEM1 is 1000 and $800 \mathrm{Gt}$, respectively. During this experiment, the grounding line retreat in the centerline of the glacier varies between 33 and $63 \mathrm{~km}$ depending on the mesh resolution and 
the melt parameterization for the Weertman sliding law, and between 42 and $75 \mathrm{~km}$ for the Tsai sliding law, with larger retreats for the FMP, SMP1, and SMP2 at coarse resolution and smaller retreats for NMP and FMP, SMP1, and SMP2 at fine resolution.

\section{Discussion}

The results presented in this study show that the impact of sub-element melt parameterization and mesh resolution is different for the Weertman and Tsai friction laws. Models relying on Weertman sliding laws are more sensitive to the mesh resolution and the type of sub-element melt parameterization than when a Tsai sliding law is employed. These conclusions are in agreement with the ones of Gladstone et al. (2017) on a flow line case. Figures 7 and 8 show the convergence of results with mesh resolution for the four sub-element mesh parameterizations. For the Weertman sliding law, the results vary by less than $2.0 \%$ for all the mesh resolutions regardless of the melt applied when NMP is used. Results using SEM1, SEM2, and FMP vary by at least 1 more order of magnitude, demonstrating that these parameterizations are more sensitive to mesh resolution than NMP in this case. When a Tsai sliding law is used, the results vary depending on the amount of sub-ice-shelf melt close to the grounding line. When melt rates converging towards zero close to the grounding line are applied, SEM1 and SEM2 converge slightly faster than FMP and NMP, and results within $5 \%$ of the $125 \mathrm{~m}$ resolution runs can be obtained for all sub-element parameterizations for mesh resolutions of $1 \mathrm{~km}$ or less. When high melt rates are applied close to the grounding line (experiment 2), NMP converges the fastest, but the behavior of SEM1 and SEM2 is close to NMP, with NMP underestimating the mass loss, while SEM1 and SEM2 overestimate it. In all cases, SEM1 and SEM2 results are almost identical (similarly to what was observed for sub-element parameterization of basal friction; see Seroussi et al., 2014a) and are intermediate between NMP and FMP. Differences between mass loss produced with NMP and FMP can be as large as $50 \%$ for $2 \mathrm{~km}$ mesh resolution (see Fig. 6). This difference is reduced as the mesh resolution increases but remains larger than $10 \%$ even at $125 \mathrm{~m}$ resolution (see Fig. 6) for high melt rates. Using the FMP never produces the best convergence of results and overestimates the mass loss by a factor of 2 in several cases; it should therefore be avoided. NMP shows the least dependence on mesh resolution, except for low melt rates close to the grounding line and a Tsai friction law (Figs. 7 and 8).

To explain this behavior, one needs to look at the numerical implementation of the equations that are affected by melt. The ocean-induced melt is only present as a right-hand-side term in the mass transport equation:

$$
\frac{\partial H}{\partial t}=-\nabla \cdot H \overline{\boldsymbol{v}}+\dot{a}-m_{\mathrm{i}},
$$

where $H$ is the ice thickness, $\overline{\boldsymbol{v}}$ is the depth-averaged ice velocity, and $\dot{a}$ is the surface mass balance. With the finiteelement method, $H$ is assumed to be a sum of nodal functions, and integrating basal melt, $m_{\mathrm{i}}$, over partially floating elements will lead to a thinning at the grounded nodes of these elements that is inherent to the finite-element method. In other words, applying melt in partially floating elements will induce a thinning upstream of the grounding line that is purely numerical, and the grounding line retreat will therefore be systematically overestimated. Using the no-melt parameterization, no numerical thinning is applied to the grounded nodes of partially floating elements. Additional experiments, not shown here, confirm that, even with a perfectly static marine ice sheet system (i.e., zero velocity at all time), the grounding line will artificially retreat, except for the NMP, regardless of the numerical method adopted. This confirms that including some basal melting in partially floating elements or cells will overestimate grounding line retreat or may lead to grounding line retreat in cases where the grounding line should theoretically not retreat. This happens despite the fact that the basal melt rate applied through SEM2 is exact (i.e., basal melting is applied only under the floating part of the domain) and independent of mesh resolution, while NMP and FMP overestimate and underestimate the total amount of basal melting, respectively.

Unlike what has been recommended for sub-element parameterizations of basal friction at the grounding line (e.g., Pattyn et al., 2006; Vieli and Payne, 2005; Feldmann et al., 2014; Seroussi et al., 2014a), using a sub-element melt parameterization therefore does not guarantee an improvement compared to simulations that do not include such implementations, nor does it necessarily relax the requirements of mesh resolutions. This is especially true when high melt rates are applied in the vicinity of the grounding line and for the Weertman sliding law. Many simulations in the Amundsen Sea sector of West Antarctica (e.g., Favier et al., 2014; Joughin et al., 2014; Seroussi et al., 2014b) applied high melt rates in this region, consistently with observations (Dutrieux et al., 2013). A previous model study performed with NMP and SEM1 in this region showed extreme differences even over 100 years, as well as a potential collapse of Thwaites Glacier in less than 100 years for high-melt-rate scenarios (Arthern and Williams, 2017). Our study sheds light on this problem, as the SEM1 was probably under-resolved, leading to an overestimation of grounding line retreat.

In this study, we only considered mesh resolutions that are $2 \mathrm{~km}$ or less. However, large-scale simulations of the Antarctic Ice Sheet typically rely on significantly coarser resolutions (e.g., Golledge et al., 2015; DeConto and Pollard, 2016; Pollard et al., 2015), especially when performing long-term simulations. In this case, using the FMP, SEM1, and SEM2 will always lead to large overestimates in the amount of mass loss and even collapse of entire regions if high melt rates are applied close to the grounding line or if experiment scenarios include high melt rates in these regions, for both Weertman 
(a) Experiment 1 Weertman

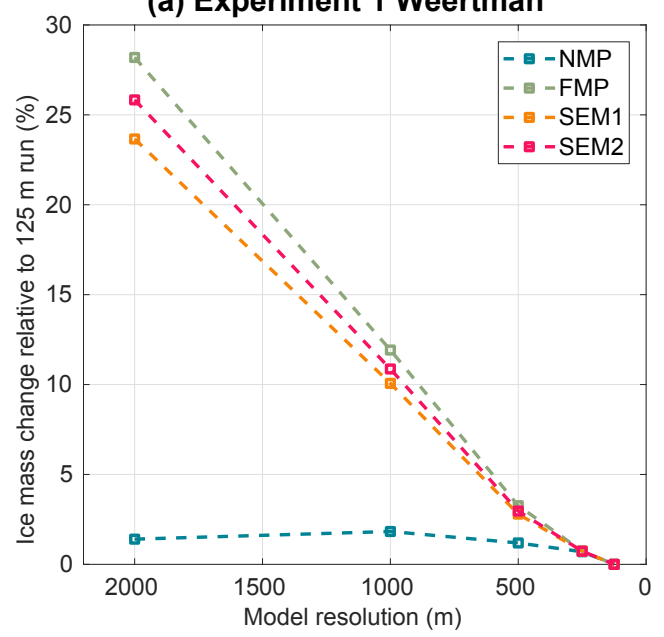

(b) Experiment 1 Tsai

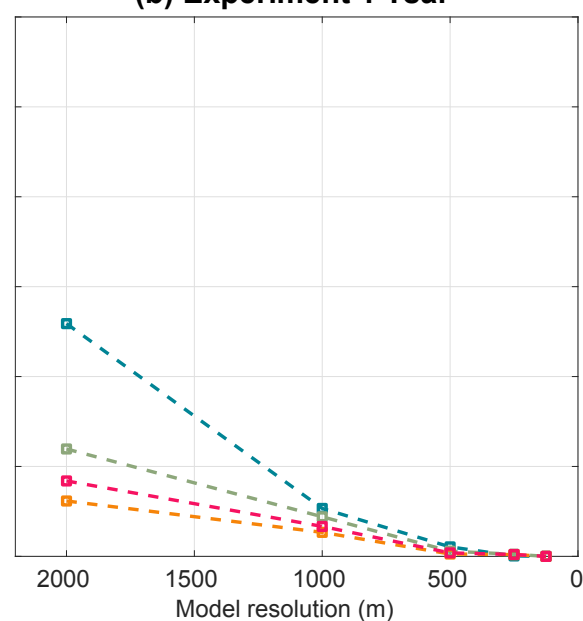

Figure 7. Convergence of ice volume above floatation at the end of experiment 1 as a function of mesh resolution. Absolute error relative to the corresponding 125 mesh resolution results (same friction law and melt parameterization scheme) for the Weertman (a) and Tsai (b) friction laws for the NMP (blue), FMP (green), SEM1 (orange), and SEM2 (red).

(a) Experiment 2 Weertman

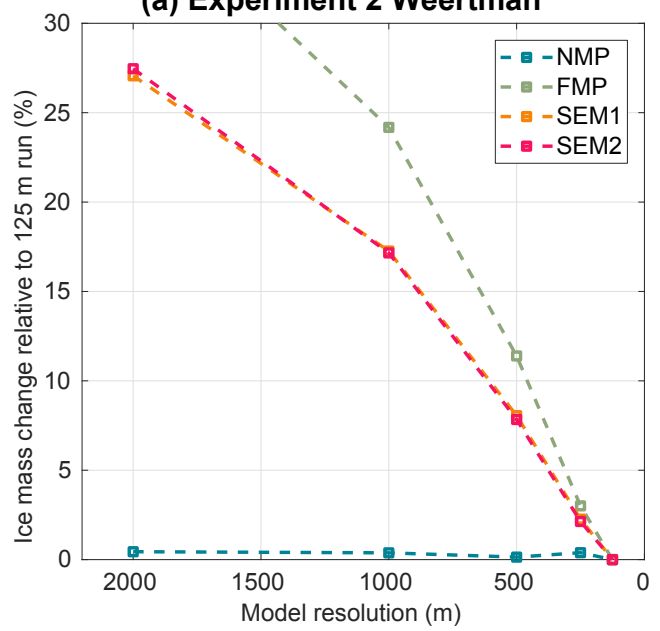

(b) Experiment 2 Tsai

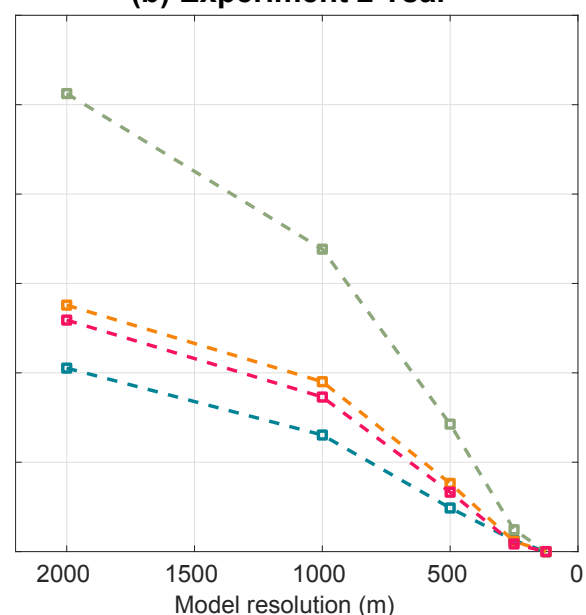

Figure 8. Convergence of ice volume above floatation at the end of experiment 2 as a function of mesh resolution. Absolute error relative to the corresponding 125 mesh resolution results (same friction law and melt parameterization scheme) for the Weertman (a) and Tsai (b) friction laws for the NMP (blue), FMP (green), SEM1 (orange), and SEM2 (red).

and Tsai sliding laws. As mentioned in previous studies (e.g., Cornford et al., 2016; Gladstone et al., 2017), quantifying the impact of mesh resolution on model results is therefore extremely important in this case in order to provide reliable estimates of uncertainties in ice sheet mass loss over the coming decades and centuries. This is especially important when simulating the collapse of marine-terminating glaciers resting on retrograde bed slope that are sensitive to the marine ice sheet instability (MISI; Weertman, 1974), as such an instability would be potentially simulated several centuries too early if ice shelf melt rates are applied on partially floating elements (Arthern and Williams, 2017; Golledge et al., 2015).
The results presented here were all performed on simulations that experience grounding line retreat and no grounding line advance. As most glaciers around the world are experiencing sustained retreat in response to climate change, cases of grounding line advance are less common. The numerical scheme or resolution needed to correctly reproduce grounding line advance are, however, different than those needed to accurately capture grounding line retreat: Gladstone et al. (2017) showed that convergence was even worse in the case of grounding line advance. It is even more critical to perform convergence tests in such a case.

Grounding lines are constantly migrating, not only on long timescales due to changes in oceanic or atmospheric con- 
ditions but also over short timescales with tides (e.g., Gudmundsson, 2007; Le Meur et al., 2014; Padman et al., 2018). Observations show that melting in the grounding zones is complex, and tidal motion probably involves complex melt rate patterns changing on tidal timescales as grounding line advances and retreats, and tidal flexure pumps ocean water in the grounding zone (Walker et al., 2013). This process could lead to more complicated patterns than the ones used in this study, assuming that the ice shelf is in hydrostatic equilibrium. However, such processes remain poorly understood; additional studies are required to better evaluate them and should not be used as a justification for numerical model inaccuracy.

All the simulations performed in this study are based on the two-dimensional SSA. We expect, however, the results to be qualitatively similar for other stress balance approximations that determine the grounding line position based on the hydrostatic equilibrium, as melt rates in partially floating elements are treated in a similar way regardless of the stress balance approximation. Using a Stokes flow line model, Gladstone et al. (2017) demonstrate a similar greater dependence of model results when high melt rates are applied close to the grounding line and the need for stricter resolution requirements. Simulations performed with threedimensional higher-order (Pattyn, 2003) or L1L2 (Hindmarsh, 2004) models should, however, generally experience smaller changes in these cases, as previous studies have shown that SSA models tend to respond more quickly than models including vertical shear (Pattyn et al., 2013; Pattyn and Durand, 2013).

\section{Conclusions}

In this study we investigate the impact of the numerical implementation of ice shelf melt rates immediately downstream of the grounding line. We compare several sub-element parameterizations that (1) do not apply any melt over partially floating elements, (2) apply basal melt over the entire partially floating elements, or (3) apply some melt over partially floating elements. Simulations are performed with different mesh resolutions for two experiments with low and high melt rates close to the grounding line, and for Weertman and Tsai sliding laws. Our results demonstrate that, for limited melt rates on the order of $1 \mathrm{~m} \mathrm{yr}^{-1}$ close to the grounding line, all sub-element melt parameterizations behave similarly for resolutions lower than $1 \mathrm{~km}$ and $500 \mathrm{~m}$ for the Tsai and Weertman friction laws, respectively. For high melt rates on the order of $30 \mathrm{~m} \mathrm{yr}^{-1}$ just downstream of the grounding line, however, models based on varying resolutions and sub-element melt rates behave differently. Both (2) and (3) overestimate the mass loss, and resolutions well below $500 \mathrm{~m}$ are needed, while (1) shows a behavior that is less dependent on the mesh resolution. These results were performed using the finiteelement method but can be extrapolated to other numerical methods, such as the finite-element and finite-volume methods. As continental-scale simulations of Antarctica typically use resolutions of several kilometers in the grounding line region, we therefore recommend models not to apply ice shelf melt rates over the entire partially floating elements and to carefully assess the impact of mesh resolution and subelement melt parameterization on all simulation results.

Data availability. All simulations shown in this paper were performed using the open-source code ISSM (https://issm.jpl.nasa. gov/). The MISMOMIP setup is described in detail in Asay-Davis et al. (2016). Data are available upon request to H.S.

Author contributions. HS and MM designed the experiments, HS conducted the runs, and all authors contributed to the manuscript.

Competing interests. The authors declare that they have no conflict of interest.

Acknowledgements. The research was carried out at the Jet Propulsion Laboratory, California Institute of Technology, under a contract with the National Aeronautics and Space Administration. Funding was provided by grants from the NASA Cryospheric Science Program and Jet Propulsion Laboratory Research Technology and Development Program. Resources supporting this work were provided by the NASA High-End Computing (HEC) Program through the NASA Advanced Supercomputing (NAS) Division at Ames Research Center. We thank Stephen Cornford and the two reviewers, Rupert Gladstone and Daniel Martin, for their constructive comments, which improved the clarity of the paper.

Edited by: Olivier Gagliardini

Reviewed by: Daniel Martin and Rupert Gladstone

\section{References}

Arthern, R. and Williams, C.: The sensitivity of West Antarctica to the submarine melting feedback, Geophys. Res. Lett., 44, 2352 2359, https://doi.org/10.1002/2017GL072514, 2017.

Asay-Davis, X. S., Cornford, S. L., Durand, G., Galton-Fenzi, B. K., Gladstone, R. M., Gudmundsson, G. H., Hattermann, T., Holland, D. M., Holland, D., Holland, P. R., Martin, D. F., Mathiot, P., Pattyn, F., and Seroussi, H.: Experimental design for three interrelated marine ice sheet and ocean model intercomparison projects: MISMIP v. 3 (MISMIP +), ISOMIP v. 2 (ISOMIP +) and MISOMIP v. 1 (MISOMIP1), Geosci. Model Dev., 9, 24712497, https://doi.org/10.5194/gmd-9-2471-2016, 2016.

Berger, S., Drews, R., Helm, V., Sun, S., and Pattyn, F.: Detecting high spatial variability of ice shelf basal mass balance, Roi Baudouin Ice Shelf, Antarctica, The Cryosphere, 11, 2675-2690, https://doi.org/10.5194/tc-11-2675-2017, 2017.

Brondex, J., Gagliardini, O., Gillet-Chaulet, F., and Durand, G.: Sensitivity of grounding line dynamics to 
the choice of the friction law, J. Glaciol., 63, 854-866, https://doi.org/10.1017/jog.2017.51, 2017.

Cornford, S. L., Martin, D. F., Lee, V., Payne, A. J., and Ng, E.: Adaptive mesh refinement versus subgrid friction interpolation in simulations of Antarctic ice dynamics, Ann. Glaciol., 57, 73, https://doi.org/10.1017/aog.2016.13, 2016.

DeConto, R. and Pollard, D.: Contribution of Antarctica to past and future sea-level rise, Nature, 531, 591-597, https://doi.org/10.1038/nature17145, 2016.

Dutrieux, P., Vaughan, D. G., Corr, H. F. J., Jenkins, A., Holland, P. R., Joughin, I., and Fleming, A. H.: Pine Island glacier ice shelf melt distributed at kilometre scales, The Cryosphere, 7, 15431555, https://doi.org/10.5194/tc-7-1543-2013, 2013.

Favier, L., Durand, G., Cornford, S. L., Gudmundsson, G. H., Gagliardini, O., Gillet-Chaulet, F., Zwinger, T., Payne, A. J., and Le Brocq, A.: Retreat of Pine Island Glacier controlled by marine ice-sheet instability, Nat. Clim. Change, 4, 117-121, https://doi.org/10.1038/NCLIMATE2094, 2014.

Feldmann, J., Albrecht, T., Khroulev, C., F., P., and Levermann, A.: Resolution-dependent performance of grounding line motion in a shallow model compared with a full-Stokes model according to the MISMIP3d intercomparison, J. Glaciol., 60, 353-359, https://doi.org/10.3189/2014JoG13J093, 2014

Gladstone, R. M., Lee, V., Vieli, A., and Payne, A. J.: Grounding line migration in an adaptive mesh ice sheet model, J. Geophys. Res., 115, 1-19, https://doi.org/10.1029/2009JF001615, 2010.

Gladstone, R. M., Warner, R. C., Galton-Fenzi, B. K., Gagliardini, O., Zwinger, T., and Greve, R.: Marine ice sheet model performance depends on basal sliding physics and sub-shelf melting, The Cryosphere, 11, 319-329, https://doi.org/10.5194/tc-11319-2017, 2017.

Golledge, N. R., Kowalewski, D. E., Naish, T. R., Levy, R. H., Fogwill, C. J., and Gasson, E. G. W.: The multi-millennial Antarctic commitment to future sea-level rise, Nature, 526, p. 421, https://doi.org/10.1038/nature15706, 2015.

Gudmundsson, G. H.: Tides and the flow of Rutford ice stream, West Antarctica, J. Geophys. Res., 112, 1-8, https://doi.org/10.1029/2006JF000731, 2007.

Gudmundsson, G. H.: Ice-shelf buttressing and the stability of marine ice sheets, The Cryosphere, 7, 647-655, https://doi.org/10.5194/tc-7-647-2013, 2013.

Gudmundsson, G. H., Krug, J., Durand, G., Favier, L., and Gagliardini, O.: The stability of grounding lines on retrograde slopes, The Cryosphere, 6, 1497-1505, https://doi.org/10.5194/tc-61497-2012, 2012.

Hindmarsh, R.: A numerical comparison of approximations to the Stokes equations used in ice sheet and glacier modeling, J. Geophys. Res., 109, 1-15, https://doi.org/10.1029/2003JF000065, 2004.

Joughin, I., Smith, B., and Medley, B.: Marine Ice Sheet Collapse Potentially Underway for the Thwaites Glacier Basin, West Antarctica, Science, 344, 735-738, https://doi.org/10.1126/science.1249055, 2014.

Larour, E., Seroussi, H., Morlighem, M., and Rignot, E.: Continental scale, high order, high spatial resolution, ice sheet modeling using the Ice Sheet System Model (ISSM), J. Geophys. Res., 117, 1-20, https://doi.org/10.1029/2011JF002140, 2012.

Lazeroms, W. M. J., Jenkins, A., Gudmundsson, G. H., and van de Wal, R. S. W.: Modelling present-day basal melt rates for Antarc- tic ice shelves using a parametrization of buoyant meltwater plumes, The Cryosphere, 12, 49-70, https://doi.org/10.5194/tc12-49-2018, 2018.

Leguy, G. R., Asay-Davis, X. S., and Lipscomb, W. H., Parameterization of basal friction near grounding lines in a onedimensional ice sheet model, The Cryosphere, 8, 1239-1259, https://doi.org/10.5194/tc-8-1239-2014, 2014.

Le Meur, E., Sacchettini, M., Garambois, S., Berthier, E., Drouet, A. S., Durand, G., Young, D., Greenbaum, J. S., Holt, J. W., Blankenship, D. D., Rignot, E., Mouginot, J., Gim, Y., Kirchner, D., de Fleurian, B., Gagliardini, O., and GilletChaulet, F.: Two independent methods for mapping the grounding line of an outlet glacier - an example from the Astrolabe Glacier, Terre Adélie, Antarctica, The Cryosphere, 8, 13311346, https://doi.org/10.5194/tc-8-1331-2014, 2014.

MacAyeal, D. R.: Large-scale ice flow over a viscous basal sediment: Theory and application to Ice Stream B, Antarctica, J. Geophys. Res., 94, 4071-4087, 1989.

Padman, L., Siegfried, M. R., and Fricker, H. A.: Ocean tide influences on the Antarctic and Greenland ice sheets, Rev. Geophys., 56, 142-184, https://doi.org/10.1002/2016RG000546, 2018.

Pattyn, F.: A new three-dimensional higher-order thermomechanical ice sheet model: Basic sensitivity, ice stream development, and ice flow across subglacial lakes, J. Geophys. Res., 108, 115, https://doi.org/10.1029/2002JB002329, 2003.

Pattyn, F. and Durand, G.: Why marine ice sheet model predictions may diverge in estimating future sea level rise, Geophys. Res. Lett., 40, 4316-4320, https://doi.org/10.1002/grl.50824, 2013.

Pattyn, F., Huyghe, A., De Brabander, S., and De Smedt, B.: Role of transition zones in marine ice sheet dynamics, J. Geophys. Res.Earth, 111, 1-10, https://doi.org/10.1029/2005JF000394, 2006.

Pattyn, F., Schoof, C., Perichon, L., Hindmarsh, R. C. A., Bueler, E., de Fleurian, B., Durand, G., Gagliardini, O., Gladstone, R., Goldberg, D., Gudmundsson, G. H., Huybrechts, P., Lee, V., Nick, F. M., Payne, A. J., Pollard, D., Rybak, O., Saito, F., and Vieli, A.: Results of the Marine Ice Sheet Model Intercomparison Project, MISMIP, The Cryosphere, 6, 573-588, https://doi.org/10.5194/tc-6-573-2012, 2012.

Pattyn, F., Perichon, L., Durand, G., Favier, L., Gagliardini, O., Hindmarsh, R. C. A., Zwinger, T., Albrecht, T., Cornford, S., Docquier, D., Fuerst, J., Goldberg, D., Gudmundsson, H., Humbert, A., Hutten, M., Huybrecht, P., Jouvet, G., Kleiner, T., Larour, E., Martin, D., Morlighem, M., Payne, A., Pollard, D., Ruckamp, M., Rybak, O., Seroussi, H., Thoma, M., and Wilkens, N.: Grounding-line migration in plan-view marine ice-sheet models: results of the ice2sea MISMIP3d intercomparison, J. Glaciol., 59, 410-422, https://doi.org/10.3189/2013JoG12J129, 2013.

Pollard, D., DeConto, R. M., and Alley, R. B.: Potential Antarctic Ice Sheet retreat driven by hydrofracturing and ice cliff failure, Earth Planet. Sc. Lett., 412, 112-121, https://doi.org/10.1016/j.epsl.2014.12.035, 2015.

Pritchard, H. D., Ligtenberg, S. R. M., Fricker, H. A., Vaughan, D. G., van den Broeke, M. R., and Padman, L.: Antarctic icesheet loss driven by basal melting of ice shelves, Nature, 484 , 502-505, https://doi.org/10.1038/nature10968, 2012.

Reese, R., Albrecht, T., Mengel, M., Asay-Davis, X., and Winkelmann, R.: Antarctic sub-shelf melt rates via PICO, The 
Cryosphere, 12, 1969-1985, https://doi.org/10.5194/tc-12-19692018, 2018.

Rignot, E., Jacobs, S., Mouginot, J., and Scheuchl, B.: Ice shelf melting around Antarctica, Science, 341, 266-270, https://doi.org/10.1126/science.1235798, 2013.

Seroussi, H., Morlighem, M., Larour, E., Rignot, E., and Khazendar, A.: Hydrostatic grounding line parameterization in ice sheet models, The Cryosphere, 8, 2075-2087, https://doi.org/10.5194/tc-8-2075-2014, 2014a.

Seroussi, H., Morlighem, M., Rignot, E., Mouginot, J., Larour, E., Schodlok, M., and Khazendar, A.: Sensitivity of the dynamics of Pine Island Glacier, West Antarctica, to climate forcing for the next 50 years, The Cryosphere, 8, 1699-1710, https://doi.org/10.5194/tc-8-1699-2014, 2014b.

Seroussi, H., Nakayama, Y., Larour, E., Menemenlis, D., Morlighem, M., Rignot, E., and Khazendar, A.: Continued retreat of Thwaites Glacier, West Antarctica, controlled by bed topography and ocean circulation, Geophys. Res. Lett., 44, 2017GL072910, https://doi.org/10.1002/2017GL072910, 2017.
Tsai, V., Stewart, A., and Thompson, A.: Marine ice-sheet profiles and stability under Coulomb basal conditions, J. Glaciol., 61, 205-215, https://doi.org/10.3189/2015JoG14J221, 2015.

Vieli, A. and Payne, A.: Assessing the ability of numerical ice sheet models to simulate grounding line migration, J. Geophys. Res., 110, 1-18, https://doi.org/10.1029/2004JF000202, 2005.

Walker, R., Parizek, B., Alley, R., Anandakrishnan, S., Riverman, K., and Christianson, K.: Ice-shelf tidal flexure and subglacial pressure variations, Earth Planet. Sc. Lett., 361, 422-428, https://doi.org/10.1016/j.epsl.2012.11.008, 2013.

Weertman, J.: On the sliding of glaciers, J. Glaciol., 3, 33-38, 1957.

Weertman, J.: Stability of the junction of an ice sheet and an ice shelf, J. Glaciol., 13, 3-11, 1974. 